\title{
Metrically conditioned pitch and layered feet in Chugach Alutiiq
}

\author{
Violeta Martínez-Paricio and René Kager \\ Universitat de València \& Utrecht University \\ violeta.martinez@uv.es,r.w.j.kager@uu.nl
}

Received: 28/01/2016. Accepted: 16/07/2016. Published on line: 19/01/2017

Citation / Cómo citar este artículo: Martínez-Paricio, V. and Kager, R. (2016). Metrically conditioned pitch and layered feet in Chugach Alutiiq. Loquens, 3(2), e030. doi: http://oadoi.org/10.3989/loquens.2016.030

\begin{abstract}
This article presents a reanalysis of the foot-based phonology of Chugach Alutiiq (henceforth CA), a language that displays a complex mixed ternary-binary rhythm, as well as metrically conditioned distributions of pitch, fortition and vowel lengthening. Elaborating on earlier analyses of CA that had posited some kind of ternary constituent (Hewitt, 1991, 1992; Leer, 1985a, 1985b, 1985c; Rice, 1992), we propose CA should be analyzed by means of the Internally Layered Ternary (ILT) foot, a minimal recursive foot (Prince, 1980; Selkirk, 1980), which was recently revived in a typological study of binary-ternary stress (Martínez-Paricio \& Kager, 2015). It will be argued that ILT feet capture CA's puzzling dual behavior of unstressed and stressed syllables straightforwardly by referring to the status of syllables as heads or dependents of minimal or non-minimal feet. After showing the value of ILT feet in the analysis of CA rhythmic and segmental patterns, we turn to our analytical focus, the distributions of high and low pitch. This distribution is arguably metrically conditioned, yet an analysis based on stress or standard binary feet cannot capture it, whereas the ILT approach can. To highlight the advantages of our approach, we end by offering brief comparisons with previous analyses of CA.
\end{abstract}

Keywords: metrical phonology; phonological representations; ternary stress; metrically conditioned pitch.

RESUMEN: Tonos condicionados por la estructura métrica y pies mínimamente recursivos en Chugach Alutiiq. Este artículo presenta un reanálisis de diversos aspectos fonológicos de la lengua esquimal Chugach Alutiiq (de ahora en adelante, CA): la asignación de acentos rítmicos (binarios y ternarios), la distribución de los tonos alto y bajo, el fortalecimiento de algunas consonantes y el alargamiento de determinadas vocales. Influidos por análisis previos de la lengua que postularon la existencia de algún tipo de constituyente prosódico ternario en CA (Hewitt, 1991, 1992; Leer 1985a, 1985b, 1985c; Rice, 1992), proponemos que la fonología métrica de CA debe analizarse por medio de un pie Ternario Mínimamente Recursivo (TMR); estas estructuras fueron originariamente propuestas por Prince (1980) y Selkirk (1980), y han sido recientemente retomadas en un estudio tipológico sobre el ritmo binario y ternario (Martínez-Paricio \& Kager, 2015). A lo largo del artículo se demostrará que todos estos procesos pueden recibir un análisis fonológico sencillo si se incorporan, entre las posibles representaciones métricas del lenguaje, los pies TMR. Concretamente, se demostrará que el pie TMR permite dar cuenta del comportamiento dual de las sílabas tónicas y átonas en CA mediante la referencia al estatus específico de estas sílabas bien como núcleos o dependientes de un pie mínimo o no mínimo. Tras resaltar el papel que desempeñan los pies recursivos en diversos patrones rítmicos y segmentales de CA, nos centramos en el análisis de la distribución de los tonos alto y bajo en esta lengua. El artículo se cierra con una breve comparación con otros análisis alternativos.

Palabras clave: fonología métrica; representaciones fonológicas; acento ternario; tono condicionado por la estructura métrica. 


\section{INTRODUCTION}

\subsection{The dual role of metrical feet}

The recognition of an intermediate rhythmic category lying between the syllable $(\sigma)$ and the prosodic word $(\omega)$, the foot $(\mathrm{Ft})$, has led to enormous insights in metrical analyses of stress assignment (Hayes, 1980/1985, 1995; Hyman, 1985; Kager, 1989; Liberman, 1975; Liberman \& Prince, 1977; Selkirk, 1978, 1980; among others). These and subsequent studies show that reference to foot structure facilitates a straightforward account of crosslinguistically attested rhythmic stress patterns. Beyond the predictive power of feet in the analysis of stress distributions, the incorporation of this prosodic category in phonological representations entails another important explanatory asset. Many otherwise puzzling phonological and morphophonological processes (e.g., fortition, lenition, vowel deletion, vowel reduction, reduplication, truncation, hypocoristic formation, etc.) and a wide variety of crosslinguistic segmental and tonal distributions receive a simple explanation once the phonological component directly refers to foot constituency (foot heads vs. foot dependents), foot edges (foot initial, foot final) and/or foot types (trochee vs. iamb, moraic vs. syllabic; e.g., Hayes, 1995, and references therein). Under this view, metrical stress and metrically dependent processes are crucially connected and better comprehended when a unique foot structure is posited for a particular language.

\subsection{New assumptions regarding foot structure}

Traditionally, the standard assumptions regarding foot structure in metrical theory have been that (i) feet consist of maximally two syllables and (ii) they are universally immediately dominated by the prosodic word (e.g., Hayes, 1995; McCarthy and Prince, 1986/1996; Nespor and Vogel, 1986). An example of these assumptions is shown in (1) (parentheses signal foot boundaries).

$$
\left[\left({ }^{\prime} \sigma \sigma\right)_{\mathrm{Ft}}\right] \omega
$$

However, an alternative hypothesis (going back to Prince, 1980; Selkirk, 1980), namely that feet can be maximally trisyllabic, as long as they are binary branching and internally layered, has recently regained acceptance by a number of works that propose to reincorporate Internally Layered Ternary (ILT) feet in metrical representations, that is, binary feet with a left- or right- weak adjunct (Bennett, 2012; Kager, 2012; Martínez-Paricio,
2012, 2013; Martínez-Paricio \& Kager, 2015, and references therein). In an ILT foot, a foot is minimally expanded via prosodic adjunction of one syllable. For instance, in (2) the ILT foot arises via adjunction of a syllable to a following/preceding trochaic foot, but similar structures can arise with iambic feet.

$$
\left[\left(\sigma\left({ }^{\prime} \sigma \sigma\right)_{\mathrm{Ft}}\right)_{\mathrm{Ft}}\right] \omega \quad\left[\left((' \sigma \sigma)_{\mathrm{Ft}} \sigma\right)_{\mathrm{Ft}}\right] \omega
$$

ILT feet arise in particular languages under specific rankings of a small set of constraints regulating the size, structure and directionality of feet (Martínez-Paricio \& Kager, 2015). Likewise, in quantity-sensitive languages, ILT feet may arise via adjunction of a weak syllable to an existing foot that consists of a heavy syllable (e.g., $\left.\left[\left(\left(\sigma_{\mathrm{Heavy}}\right)_{\mathrm{Ft}} \sigma\right)_{\mathrm{Ft}}\right] \omega\right)$ (Kager \& Martínez-Paricio, forthcoming-a, forthcoming-b). The only restriction in all these layered configurations is that recursion at the foot level must be minimal, that is, just a single foot layer can be stacked on top of another foot. ${ }^{1}$

The postulation of minimal recursive feet has a venerable history in phonological theory; it finds its roots in original works on foot structure (Selkirk, 1980, and Prince, 1980) and has since occasionally been invoked in the analysis of particular languages (e.g., Grijzenhout, 1990; Hewitt, 1992; van der Hulst, 2010; Kager, 1994; McCarthy, 1982; Rice, 1992; Zoll, 2004). However, for a number of different reasons (see Hayes, 1995, and Rice, 2007,2011 , for details) ILT feet had usually been left out from mainstream metrical theory until fairly recently.

In this context, two are the main goals of this paper. The first is to provide further arguments in support of the dual role of the prosodic category foot as the domain of metrical stress and foot-dependent phonological processes in Chugach Alutiiq (CA), a dialect of the Yupik language spoken by a small number of individuals in Alaska, from Cook Inlet to the Prince William Sound (Leer, 1985a). To achieve this goal, we will specifically look at the distribution of pitch in this language and its interaction with stress, as described in Leer $(1985 a, b, c) .{ }^{2}$ The distribution of pitch in CA is especially intriguing because this seems to be tightly connected to stress. However, a purely stress-based account fails to predict its specific distribution. Consider, for example, the data in (3). The three trisyllabic words display very different pitch patterns. Whereas high $(\mathrm{H})$ tones seem to dock to stressed syllables, the distribution of low (L) tones is not that straightforward: some unstressed syllables surface with an L tone, while others don't, in a way that is not immediately apparent from their relative position with respect to

\footnotetext{
1 For the reasons behind assuming that foot recursion is restricted to only one level, as opposed to recursion in foot-external prosodic categories like the prosodic word or the phonological phrase, see Martínez-Paricio (2013) and Martínez-Paricio \& Kager (2015).

2 Although Leer's transcription often refers to a difference between primary and secondary stressed syllables, we follow Rice (1992, p. 140) in reanalyzing this contrast as a contrast in pitch; see also Leer (1985c) suggestion along these lines: "It is possible to argue that in CA we have two degrees of stress [stressed vs. unstressed] and three pitch levels [high, low, and no particular tone] and that 'weakly stressed' syllables [i.e., secondary stressed syllables] differ from 'unstressed' syllables not by stress, but in that the 'weakly stressed' syllables are assigned pitch level 1 [equivalent to a low tone], whereas the 'unstressed' syllables are not assigned a pitch level of their own. Their pitch is dependent on the pitch of neighboring syllables" (p. 164).
} 
stressed syllables. (Dots indicate syllable boundaries; stressed syllables appear in boldface with an acute accent; $\mathrm{H}$ and $\mathrm{L}$ superscripted at the right edge of a syllable indicate that the preceding syllable displays that particular pitch and ${ }_{i} \mathrm{H}$ indicates an up-stepped high.)

(3) Pitch distributions in CA (Leer, 1985a):
a. $\mathbf{a ́ n}^{\mathrm{H}} \cdot \mathrm{ci}^{\mathrm{L}}$. quá ${ }^{\mathrm{H}}$
'I'll go out'
b. aá ${ }^{\mathrm{H}}$. na. ká ${ }^{\mathrm{H}}$
'my mother'
c. mu.lú ${ }^{\mathrm{H}} \cdot \operatorname{kan}^{\mathrm{L}}$
'if she takes a long time'

We will demonstrate that a foot-based account of CA correctly predicts its particular distribution of tone. In this respect, the second, more specific goal of this article is representational, namely we will argue in favor of a metrical analysis of CA pitch and stress patterns that refers to ILT feet. We will show that these patterns, as well as other phonological processes in CA, receive a unified account when metrical representations include ILT feet. Since previous analysis of the language had already posited some kind of prosodic constituent larger than the standard binary foot and smaller than the prosodic word to account for various segmental and suprasegmental aspects of the language (e.g., the superfoot and the Pitch Group in Leer, 1985a, 1985b, 1985c; the bounded prosodic word in Hewitt, 1991, 1992; the resolved foot in Rice, 1992), we will discuss the main similarities and differences between these analyses and our ILT foot approach. Although we tacitly assume the phonological framework of Optimality Theory (Prince \& Smolensky, 1993/2004), the hierarchy of constraints responsible for creating different metrical structures in CA will not be discussed in this article, since our main goal here is to analyze the potential of ILT representations (interested readers are referred to Martínez-Paricio, 2013, and Martínez-Paricio \& Kager, 2015).

The remainder of this paper is organized as follows. Section 2 summarizes the data presented in Leer (1985a, $1985 \mathrm{~b}, 1985 \mathrm{c}$ ) and proposes an ILT-foot based analysis of CA rhythmic stress based on Martínez-Paricio (2013) and Martínez-Paricio and Kager (2015), relying on the notion of the rhythmic continuum (Martínez-Paricio \& Kager, 2015), which is useful to understand CA metrical structure. Section 3 describes and analyzes the tonal distribution of CA, providing further support for the incorporation of ILT feet in metrical representations. Section 4 provides additional vowel lengthening data in support of this view. Section 5 highlights the major divergences between previous representational analyses of CA tone and the one proposed here. Section 6 presents the conclusions.

\section{CHUGACH ALUTIIQ IN THE RHYTHMIC CONTINUUM}

Chugach Alutiiq has figured prominently in the metrical literature due to its rich prosodic system and complicated stress patterns, which combines binary and ternary rhythmic stress. ${ }^{3}$ That is, whereas in some words stress appears on every second syllable (e.g., akútamék 'kind of food-ABL-SG'), in other words stress may fall on a subsequent third syllable (e.g., atúqunikí 'if he [REFL] uses them'). Ternary stress alternations are rare from a typological point of view and they have generally posed an analytical challenge to metrical theories, whether rule based or constraint oriented (see Hayes, 1995; Rice, 2011, for references). Since feet were thought to be maximally bisyllabic and appear adjacently in a word, the motivation behind ternary stress alternations remained unclear. However, the recent revival of ILT feet has led to a new interpretation of ternarity and the typology of rhythmic stress in general, which will be reviewed in Section 2.1. Finally, CA is a weight-sensitive language and thus, the already complicated mixed rhythmic stress patterns can be further modified by the presence of heavy syllables.

This section presents the stress data in CA and proposes, following Martínez-Paricio and Kager (2015), that the foot structure in the language displays a combination of traditional binary feet and ILT feet. We first discuss metrical representations for words containing only light syllables (Section 2.1) and then turn to investigate the structure of words with heavy and light syllables (Section 2.2). All data in this article are drawn from the series of important descriptive and analytical works based on Leer's own fieldwork (1985a, 1985b, 1985c) and the extensive reanalysis found in Rice's dissertation (1992). These two studies, together with Hewitt's (1991, 1992), have greatly influenced the present one, since they already investigated the possibility of including some additional layer in between the foot and the prosodic word in CA metrical representations.

\subsection{Quantity-insensitive stress patterns}

The distribution of stress in CA words with light syllables is illustrated in (4). Chugach has multiple instances of equally prominent stresses per prosodic word (Leer, 1985a, 1985b, 1985c; Rice, 1992). Although this is not very common in stress systems, it is frequent in other Yupik languages (Jacobson, 1985; Woodbury, 1987). The data illustrate the binary and ternary rhythmic stress alternations in CA. On the leftmost column we indicate the number of syllables in each word, which, in these cases, matches the number of morae.

3 Analyses of prosodic aspects of the language include Leer (1985a, 1985b, 1985c), Halle and Vergnaud (1987), Rice (1988, 1992), Halle (1990), Hewitt (1991, 1992), Idsardi (1992), Kager (1993, 1994), Hayes (1995), Green and Kenstowicz (1996), Hammond (1995), van der Vijver (1998), Elenbaas and Kager (1999), Rosenthall and van der Hulst (1999), Hyde (2001, 2002), McCartney (2003), and Houghton (2006). 
(4) Chugach Alutiiq stress: words with light syllables ${ }^{4}$ (Leer, 1985a):

\begin{tabular}{|l|ll|}
\hline a. $2 \sigma$ & $\begin{array}{l}\text { pə.náq } \\
\text { 'cliff' }\end{array}$ & p. 104 \\
\hline b. $3 \sigma$ & $\begin{array}{l}\text { a.kú.taq } \\
\text { 'a food-ABSOLUTIVE' }\end{array}$ & p. 84 \\
\hline c. $4 \sigma$ & $\begin{array}{l}\text { a.kú.ta.mék } \\
\text { 'a food-ABLATIVE-SG' }\end{array}$ & p. 84 \\
\hline d. $5 \sigma$ & $\begin{array}{l}\text { a.tú.qu.ni.kí } \\
\text { 'if he (REFL) uses them' }\end{array}$ & p. 113 \\
\hline e. $6 \sigma$ & $\begin{array}{l}\text { pi.sú.qu.ta.qú.ni } \\
\text { 'if he (REFL) is going to hunt' }\end{array}$ & p. 113 \\
\hline f. $7 \sigma$ & $\begin{array}{l}\text { ma.nár.su.qu.tá.qu.ní } \\
\text { 'if he (REFL) is going to hunt porpoise' }\end{array}$ & p. 113 \\
\hline
\end{tabular}

In (4) we see that peninitial syllables are always stressed and final syllables are stressed with the exception of $3 n$-syllable words (i.e., 3- and 6-syllable forms, that is, $4 \mathrm{~b}$ and $4 \mathrm{e}$ ), where the rightmost stress falls on the penultimate syllable instead. Words longer than four syllables (4d-f) display a ternary stress alternation after the peninitial stress, that is, the second and fifth syllables are separated by a lapse of two unstressed syllables. However, this ternary stress alternation is not maintained throughout in words of $3 n+1$ syllables (4f); for example, in 7-syllable forms binarity reemerges after the fifth stressed syllable, which is separated by only one syllable from the subsequent stress. Based on the fact that peninitial syllables are always stressed and final stress is pre-dominant, it can be proposed that the foot shape in CA involves an iamb. With left-to-right footing, this predicts the correct location of stress in (4a-c). It remains uncertain, however, how to account for the ternary stress alternation following the first foot in longer words (4d-f) as well as the partial reemergence of binarity in 7-syllable forms (4f).
Although typologically rare, ternary stress and pitch accent alternations have been reported for a handful of languages. Martínez-Paricio and Kager's (2015) novel typological analysis of binary and ternary quantity-insensitive rhythmic stress is able to account for the attested patterns without overgenerating metrical incoherent rhythmic systems (cf. Hyde, 2015). This new analysis, couched within Optimality Theory (Prince \& Smolensky, 1993/2004), reintroduces ILT feet in metrical representations and concludes that the traditional dichotomy between binary stress systems and ternary stress systems is too strict and should be slightly relaxed. According to these authors, rhythmic stress systems cannot be strictly categorized as either binary or ternary. Instead, languages are placed along a binary-to-ternary rhythmic continuum (Table 1). At one end of the continuum (leftmost column, Table 1), we encounter languages with binary stress alternations in every length form, which result from the combination of binary feet and (in odd-numbered forms) an unparsed syllable at one edge of the prosodic word. At the other end of the continuum we find languages with radical ternarity, that is, all stressed syllables are separated by two unstressed syllables (rightmost column, Table 1). In these languages ILT are overall favored: even when two adjacent syllables could give rise to a binary foot, languages at this end of the continuum prefer to leave those two syllables unfooted. Although Table 1 illustrates the continuum with trochaic feet, $\left({ }^{1} \sigma \sigma\right)$, and trochaic feet with a right adjunct, $\left((' \sigma \sigma)_{\mathrm{Ft}} \sigma\right)_{\mathrm{Ft}}$, the continuum can also be instantiated with trochaic feet with a left adjunct and all types of binary and ILT iambic feet.

In between these two extremes, mixed systems with increasing ternarity emerge: from those where ILT feet are only a last-resort device that ensures exhaustive parsings in odd-parity forms (Bennett, 2012; Martínez-Paricio, 2012, 2013; second column in Table 1) to those where ILT feet and binary feet coexist to a different extent (third and fourth column in Table 1).

Table 1: The binary-to-ternary rhythmic continuum (Martínez-Paricio \& Kager, 2015, p. 461).

\begin{tabular}{|c|c|c|c|c|}
\hline $\begin{array}{l}\text { strictly binary } \\
\text { non-exhaustive }\end{array}$ & $\begin{array}{l}\text { binary and ternary } \\
\text { exhaustive }\end{array}$ & $\begin{array}{l}\text { ternary and binary } \\
\text { exhaustive }\end{array}$ & $\begin{array}{l}\text { ternary and binary } \\
\text { non-exhaustive }\end{array}$ & $\begin{array}{l}\text { strictly ternary } \\
\text { non-exhaustive }\end{array}$ \\
\hline$(\dot{\sigma} \sigma) \sigma$ & \multicolumn{4}{|c|}{$\left(\left(\sigma^{\prime} \sigma\right) \sigma\right)$} \\
\hline \multicolumn{3}{|c|}{$\left(\sigma^{\prime} \sigma\right)\left(\sigma^{\prime} \sigma\right)$} & \multicolumn{2}{|c|}{$((\sigma \dot{\sigma} \sigma) \sigma) \sigma$} \\
\hline$\left(\sigma^{\prime} \sigma\right)\left(\sigma^{\prime} \sigma\right) \sigma$ & \multicolumn{3}{|c|}{$((\sigma ́ \sigma) \sigma)(\sigma ́ \sigma)$} & $((\sigma \delta \sigma) \sigma) \sigma \sigma$ \\
\hline \multicolumn{2}{|c|}{$\left(\sigma^{\prime} \sigma\right)\left(\sigma^{\prime} \sigma\right)(\dot{\sigma} \sigma)$} & \multicolumn{3}{|c|}{$\left(\left(\sigma^{\prime} \sigma\right) \sigma\right)((\sigma \dot{\sigma}) \sigma)$} \\
\hline$\left(\sigma^{\prime} \sigma\right)(\sigma \dot{\sigma} \sigma)(\sigma \dot{\sigma}) \sigma$ & \multicolumn{2}{|c|}{$((\sigma \dot{\sigma} \sigma) \sigma)(\sigma ́ \sigma)(\sigma ́ \sigma)$} & \multicolumn{2}{|c|}{$((\sigma \dot{\sigma} \sigma) \sigma)\left(\left(\sigma^{\prime} \sigma\right) \sigma\right) \sigma$} \\
\hline \multicolumn{2}{|c|}{ 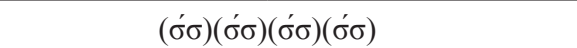 } & \multicolumn{2}{|c|}{ 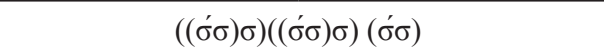 } & $(\sigma \dot{\sigma}) \sigma)((\sigma \dot{\sigma}) \sigma) \sigma \sigma$ \\
\hline
\end{tabular}

\footnotetext{
4 Following Leer (1985a) and Rice (1992), data are given in the standard orthography with the exception of the digraph $<$ ng $>$, which was substituted for its phonetic value [ $\mathrm{y}]$. The rest of the orthography is transparent, although it deviates from phonetics only in a few cases: voiced fricatives $\left[\mathrm{r}, \mathrm{x}^{\mathrm{w}}, \mathrm{\gamma}, \mathrm{\gamma}^{\mathrm{w}}\right]$ are represented as $<\mathrm{g}, \mathrm{w}, \mathrm{r}, \mathrm{rw}>$, respectively; voiceless fricatives $\left[\mathrm{t}, \mathrm{x}, \mathrm{x}^{\mathrm{w}}, \mathrm{x}\right]$ as $<1 \mathrm{l}, \mathrm{gg}, \mathrm{ggw}, \mathrm{rr}>$; and the voiceless nasal as $<\mathrm{hN}>$.
} 
On this view, CA falls somewhere near the middle of the rhythmic continuum; namely, CA would instantiate a mixed ternary/binary exhaustive system (third column in Table 1). Following Martínez-Paricio and Kager (2015), and previous analyses of CA (see references above), we assume that the default foot in CA involves an iamb, which in some occasions can have a right-adjoined syllable. This gives rise to an ILT foot of the shape shown in Figure 1. Headedness is indicated with vertical lines. In this structure a foot projection $\left(\mathrm{Ft}^{\prime}\right)$ dominates another foot $(\mathrm{Ft})$.

Figure 1: ILT foot in Chugach Alutiiq (Martínez-Paricio, 2012, 2013; Martínez-Paricio \& Kager, 2015).

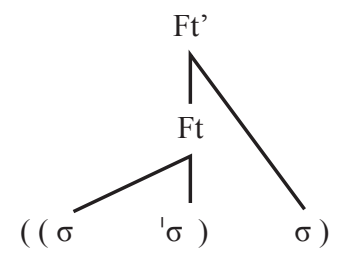

That is, in forms with light syllables only, the juxtaposition of ILT feet and disyllabic iambs gives rise to the binary-ternary mixed stress patterns reported for CA. The data with the relevant metrical representations, arranged by the number of syllables in a word is presented in (5).

(5) Chugach binary and ILT feet (Leer 1985a):

\begin{tabular}{|l|lc|}
\hline No. of $\sigma$ & \multicolumn{3}{|c|}{} \\
\hline a. 2 & $\begin{array}{l}\text { (pə.náq) } \\
\text { 'cliff' }\end{array}$ & p. 104 \\
\hline b. $3 n$ & $\begin{array}{l}\text { ((a.kú).taq) } \\
\text { 'a food-ABSOLUTIVE' } \\
\text { ((pi.sú) qu)((ta.qú) ni) } \\
\text { 'if he (REFL) is going to hunt' }\end{array}$ & p. 113 \\
\hline c. $3 n+1$ & $\begin{array}{l}\text { (a.kú)(ta.mék) } \\
\text { 'a food-ABLATIVE-SG' } \\
\text { ((ma.yár) su)(qu.tá)(qu.ní) } \\
\text { 'if he (REFL) is going to hunt porpoise' }\end{array}$ & p. 113 \\
\hline d. $3 n+2$ & $\begin{array}{l}\text { ((a.tú) qu)(ni.kí) } \\
\text { 'if he (REFL) uses them' }\end{array}$ & p. 113 \\
\hline
\end{tabular}

The general principle that regulates the parsing of syllables into feet in $\mathrm{CA}$ is the following: ternary feet are built starting at the left edge; however, in case a string of four syllables is left over at the right edge, this is broken up into two binary feet (e.g., $3 n+1$ forms, 5 c). That is, binarity is favored in these cases over ternarity in order to satisfy exhaustivity and avoid unary feet.

In 2- and 4-syllable forms $(5 \mathrm{a}, \mathrm{c})$ exhaustivity is achieved with binary feet and, therefore, there is no need for ILT feet to emerge. In 3-syllable forms, to avoid leaving one syllable unparsed, an ILT foot arises (5b). The same occurs in other $3 n$ forms: the 6-syllable form pisúqutaqúni (5b) prioritizes a parsing with two ILT feet this form rather than with three binary feet. This preference to economize in feet or gridmarks is a property of ternary systems that has always been present in the literature on ternary stress (Elenbaas \& Kager, 1999; Gordon, 2002; Hayes, 1995; Hyde, 2002; Kager, 1994, among others). However, this tendency towards economizing in number of feet is not radical: in a 7-syllable form, two ILT feet could have been built, but this would have left one syllable either unparsed or in a degenerate foot. None of these options are possible in CA (see Martínez-Paricio \& Kager, 2015, for a complete constraint-based analysis of rhythmic stress).

The representations in (5) are further supported by another phonological process: Leer (1985a, b, c) and Rice (1992) report that CA displays fortition of consonants at the left edge of a foot. This type of foot-initial strengthening, shown in (6), can be correctly predicted assuming the parsings in (5) where the left edge of every foot (binary or ILT) is the target of fortition (fortis consonants are underlined).

(6) Foot-initial fortition:
a. (pə.náq)
b. ((pi.sú) qu) ((ta.qú) ni)

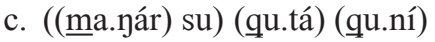

In the following subsection we briefly discuss the stress patterns in forms with heavy syllables, which resemble the ones presented here, with the only exception that heavy syllables attract stress and moraic structure is crucial.

\subsection{Quantity-insensitive stress patterns}

In CA there are two types of heavy bimoraic syllables: (i) syllables with long vowels and diphthongs and (ii) word-initial closed syllables ( $\mathrm{CVC}$ ). The fact that $\mathrm{CVC}$ are exclusively bimoraic in word-initial position is not typologically odd, since contextual restrictions on moraic consonants have been reported for various languages (Hayes, 1995; Kager, 1989; Rosenthall \& van der Hulst, 1999). We interpret this positionally restricted coda weight in word-initial syllables as an instance of prominence enhancement in a phonologically strong position since the left edge of the prosodic word has been claimed to be a strong position from a phonetic, psycholinguistic and phonological point of view (Beckman, 1998; Smith, 2005, and references therein). ${ }^{5}$

In CA, heavy syllables always attract stress, altering the stress patterns reviewed in Section 2.1. To illustrate this, consider the data in (7):

(7) Chugach Alutiiq stress: words containing heavy syllables (Leer, 1985a):
a. taá.ta.qá
'my father' (p. 86)
b. taá.taá

\footnotetext{
${ }^{5}$ Additional support for the relevance of the word-initial position in CA comes from a process of gemination, which only targets wordinitial light syllables that are followed by a heavy syllable (see Martínez-Paricio, 2013, p. 169 for details).
} 

c. mu.lúk.'uút
d. naá.'uq
e. úl.luá
f. án.ci.quá
g. án.ci.qu.kút
h. qáy.yaá.kun
i. naá.ma.cí.quá
j. ág.ku.tár.tuá.na
k. naá.qu.ma.lú.ku

Compare the metrical structures of (9a) and (9b). Although both contain 6 morae, one of them is parsed with two ILT feet (naáqumalúku, 9a) whereas the other is parsed with three binary feet (naámacíquá, 9b). How is this possible? In the first form (9a), just as it occurred in forms with light syllables (cf. 5b), there are two ILT feet to economize in number of ILT feet. In contrast, in (9b) there are three binary feet, with no adjunction. This is so because both the first and final syllables are heavy and, thus, constitute a foot on their own. Whereas the third syllable could have been adjoined to the preceding foot, the fourth syllable cannot be adjoined to the following foot as in (9b"): this would create a left-adjunct ILT foot, which is ill-formed in CA. Nor can the third syllable project a foot of its own as in (9b'): this syllable is monomoraic and CA does not allow monomoraic feet. Within Optimality Theory, the representations in (9) can be regulated via the interaction of specific constraints on foot form, foot size and constraints governing the distribution of feet within a word (see Kager \& Martínez-Paricio, forthcoming $a$, forthcoming $b$, for an analysis of rhythmic stress in quantity-sensitive languages with ILT feet).

\section{PITCH}

In this section we demonstrate that the ILT foot structure proposed in Section 2 for CA is precisely needed to account for the distribution of pitch in the language. Leer (1985c) reported that syllables in CA can exhibit one of three different options regarding their pitch: they can bear a high tone $(\mathrm{H})$, a low tone $(\mathrm{L})$ or, under specific circumstances, they remain unspecified for tone; the pitch of these syllables depends on the pitch of neighboring syllables (p. 164). Importantly, CA pitch is not lexically specified, but its distribution is determined exclusively by metrical structure (Hewitt, 1991, 1992; Leer, 1985c; Rice, 1992). In this section we will see that the representation that best accounts for the pitch patterns in CA is an ILT foot like the one proposed in Section 2: a moraic iamb with a right adjunct. To illustrate the distribution of pitch in CA, (10) first provides some words with light syllables with their respective pitch contours, according to Leer's descriptions (1985c, pp. 168-170).

(10) Pitch patterns: words with light syllables (Leer, 1985c):
a. ta. $q u^{\mathrm{H}} \cdot m a^{\mathrm{L}} \cdot \mathbf{l u} \cdot \mathrm{ni}^{\mathrm{H}}$
b. pi. $\operatorname{sú}^{\mathrm{H}} \cdot \mathrm{qu}^{\mathrm{L}}$. ta. $q \mathbf{q u}^{\mathrm{H}} \cdot \mathrm{ni}^{\mathrm{L}}$
c. a. $\mathbf{k u ́}^{\mathrm{H}} \cdot$ ta. mék ${ }^{\mathrm{iH}}$
d. a.tá ${ }^{\mathrm{H}} \cdot \mathrm{ka}^{\mathrm{L}}$

As can be seen in (10), stressed syllables are always high, and some of them are up-stepped $\left({ }_{i} \mathrm{H}\right.$; see the final

\footnotetext{
${ }^{6}$ In CA orthography, the apostrophe (") is sometimes used to indicate that a preceding $\mathrm{C}$ is a geminate or that a fricative has been dropped. In the latter case the orthographic representation is based on the underlying morphology and does not have any effect on the phonetic form (Leer, 1985a, p. 98).

7 Leer explicitly states that a long vowel's or diphthong's second mora is the head of the foot; that is, long vowels have a rising (or iambic) contour.
} 
syllable in $10 \mathrm{c}) . \mathrm{H}$ is up-stepped when it is preceded by another $\mathrm{H}$ and there is no intervening $\mathrm{L}$ between the two highs (10c). A high tone will not be up-stepped if the preceding $\mathrm{H}$ is already up-stepped, that is, in CA up-stepping does not chain (e.g., án $\boldsymbol{n}^{H} . k u . t a ́ \boldsymbol{r}^{i H} . \boldsymbol{t} \boldsymbol{t} \boldsymbol{a}^{H}$ 'I'm going to go out'; Leer, 1985a, p. 116). Therefore, the up-stepping can be interpreted as an Obligatory Contour Principle (OCP) effect (Hewitt, 1991, p. 55). The attraction of $H$ to stressed syllables (i.e., foot heads) is common in mixed prosodic systems with tone and stress, and various rules and constraints have been proposed to account for this universal tendency (e.g., Bickmore, 1995; de Lacy, 2002, 2004, 2006; Goldsmith, 1987). Likewise, the up-stepping of an $\mathrm{H}$ when preceded by another $\mathrm{H}$ is well known from the literature of tone and intonation (Goldsmith, 1976; Gussenhoven, 2004; Pierrehumbert, 1980; Yip, 2002, etc.) and can be easily captured by a simple rule or via constraint interaction.

In optimality theory terms, it can be argued that the up-stepping of certain high tones results from a highranked OCP constraint, which avoids a sequence of two high tones by up-stepping the second one $\left(\mathrm{HH} \rightarrow \mathrm{H}_{i} \mathrm{H}\right){ }^{8}$ When this constraint is high ranked, it predicts that upstepping will not apply to all $\mathrm{H}$ syllables, but acts minimally so as to avoid violations of the OCP constraint. This prediction is borne out in CA, where a sequence of four high tones is resolved by up-stepping the second and fourth $\mathrm{H}$ syllables in a form like $a^{g^{\mathrm{H}}} \cdot \eta_{u a^{\prime}}{ }^{\mathrm{H}} \cdot q u \cdot t^{\prime} r^{\mathrm{H}} \cdot \underline{t u a ́}^{i \mathrm{H}}$. $\eta a^{\mathrm{L}}$ 'I'm going to dance' (Leer, 1985c, p. 170). That is, up-stepping applies twice in a sequence of four $\mathrm{H}$ tones. The up-stepping of the second and fourth $\mathrm{H}$ tones in $a^{\mathrm{H}}{ }^{\mathrm{H}}$. $\eta_{u a^{i \mathrm{H}}} \cdot q u \cdot t_{a} r^{\mathrm{H}} \cdot \underline{t u a ́}^{i \mathrm{H}} \cdot y^{\mathrm{L}}$ makes sense using an OCP constraint: up-stepping one high tone would clearly not be enough, since there would still be an OCP violation, so two up-stepped high tones are needed. To avoid OCP violations in the most economical way, an alternating pattern of up-stepping is created.

As anticipated in Section 1, what is puzzling in CA is the distribution of lows: while some unstressed syllables are assigned an L (e.g., the third syllable in 10a, 10b and 10d), other unstressed syllables do not receive any particular tone, their pitch being an interpolation between neighboring tones (e.g., the first and fourth syllables in $10 \mathrm{a}-\mathrm{b}$, the third syllable in 10c). If one considers the data in (10), a non-structural stress-based explanation for the pitch patterns could be proposed. Namely, it could be argued that an L docks onto every post-stress syllable that is not immediately followed by a high-pitched syllable. This approach derives the correct distribution of pitch in words with light syllables (10a-d). However, when words with heavy syllables are taken into consideration, the stress-based account proves inadequate, being unable to predict the presence or absence of lows. This is shown in (11a-b), where the pitch patterns of two words with heavy syllables are considered. These words have similar length (both are trisyllabic) and stress occurs on exactly the same syllables (i.e., the first and third syllables). However, they differ in their pitch melodies: in (11a) the second syllable bears a low pitch, whereas the second syllable in (11b) does not. Therefore, a strictly stress-based account of the distribution of pitch in CA fails to capture the pitch differences between these two forms, since stress falls on the same syllables (first and third), yet their pitch patterns are different.

(11) Pitch patterns: light and heavy syllables (Leer, 1985a):

\begin{tabular}{|c|c|}
\hline \multicolumn{2}{|c|}{ Tonal patterns } \\
\hline a. án ${ }^{\mathrm{H}} \cdot \mathrm{ci}^{\mathrm{L}} \cdot \mathbf{q u a ́}{ }^{\mathrm{H}}$ & p. 115 \\
\hline b. taá ${ }^{\mathrm{H}}$. ta. $\mathbf{q} \mathbf{a}^{\mathbf{i}}$ & p. 86 \\
\hline
\end{tabular}

In a model that allows reference to ILT feet, the difference in pitch between unstressed syllables in (11a) vs. (11b) can be easily captured since the same ILT metrical structure needed for stress can now straightforwardly account for the distribution of pitch in CA as well. In particular, we propose that CA exploits the distinction between the two types of foot dependents in the ILT foot: (i) the dependent of the minimal projection of a foot $\left(\sigma_{\mathrm{A}}\right.$ in Figure 2) and (ii) the dependent located in the adjunct position $\left(\sigma_{\mathrm{B}}\right.$ in Figure 2), that is, the dependent of a nonminimal projection of a foot. More specifically, our proposal is that in CA an L only docks onto unstressed syllables that are in an adjunct position, that is, that are directly dominated by a non-minimal foot (i.e., a foot dominating another foot), whereas no specific pitch accent is assigned to immediate dependents of a minimal foot (i.e., a foot that is not dominating a foot; terminology borrowed from Ito \& Mester, 2007, 2009, 2013).

Figure 2: Two types of foot dependents (Martínez-Paricio, 2013).

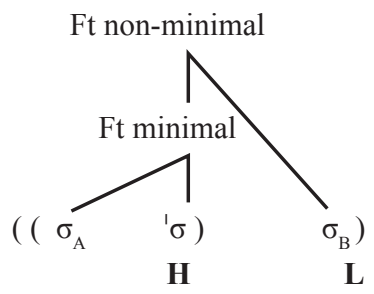

This representational analysis is illustrated in (12) and it correctly predicts that no L will occur in a word in the absence of an ILT foot (12b). In this sense, the ILT foot approach is able to provide a unified account of both stress and tone in the language.

(12) Distribution of $\mathrm{H}$ and L:

\begin{tabular}{|l|}
\hline \multicolumn{1}{|c|}{ Tonal patterns } \\
\hline a. $\left(\left(\mathbf{a ́ n}^{\mathrm{H}}\right) \mathrm{ci}^{\mathrm{L}}\right)\left(\mathbf{q u a ́}{ }^{\mathrm{H}}\right)$ \\
\hline b. $\left(\right.$ taá $\left.^{\mathrm{H}}\right)\left(\right.$ ta. $\left.q \mathbf{a}^{\mathrm{iH}}\right)$ \\
\hline
\end{tabular}

\footnotetext{
${ }^{8}$ Note that the OCP constraint itself does not select a particular $\mathrm{H}$ tone to be up-stepped (i.e., here the 2 nd $\mathrm{H}$ in a $\mathrm{HH}$ sequence, not the first). This choice follows from other constraints not discussed here.
} 
The distribution of pitch in CA, thus, constitutes additional empirical evidence for the need of recursive footing in natural languages. Namely, the recursion-based representational device allows the different behavior of the two types of unstressed syllables to be captured (further support for this idea can be found in Davis \& Cho, 2003; Jensen, 2000; Kager \& Martínez-Paricio, forthcoming-a). This particular interpretation of the facts also explains why we never encounter rising and falling pitch contours within a single heavy syllable: a syllable that has two morae always constitutes a foot of its own, but this foot is always minimal and, therefore, an L cannot be docked onto it.

\section{LENGTHENING}

Leer $(1985 \mathrm{c})$ reports that in CA stressed vowels are generally lengthened in syllables that are not closed by a consonant (e.g., akú :tamék). Interestingly, Leer notes a subtle durational difference among lengthened vowels: some of them are longer than the rest. For instance, when comparing the duration of the second syllable in akútaq 'a food-ABSOLUTIVE' (13a) and akútamék' 'a food-ABLATIVESG' (13b) Leer states: "the syllable $k u$ is lengthened in both cases, but $u$ is longer in akutaq" (1985c, p. 164).

\section{(13) a. a.kú $\cdot \operatorname{taq}$ 'a food-ABSOLUTIVE' \\ b. a.kú:.ta.mék 'a food-ABLATIVE-SG'}

This durational difference between the two words is, as we will show, relatively straightforward if one considers the differences between their metrical structures in a model with ILT feet, as can be seen in (14):

(14) ILT foot model:
a. ((a.kú:) taq)
b. (a.kú́)(ta.mék)

The $u$ in akútaq (14a) can be argued to be longer than the $u$ one in akútamék (14b) due to its double-head status: the former is simultaneously the head of two feet, a minimal foot and a non-minimal foot (based on Martínez-Paricio, 2012). Syllables in the foot head are often lengthened in many languages, and thus it is likely that a syllable that is the head of two foot projections is singled out as the target of lengthening too. In that sense, the length distinction between (13a) and (13b) can be understood as a prosodic prominence effect.

An alternative purely phonetic account of the facts, which is also valid, can be found in Hayes (1995). This author claims that the lengthening process is inhibited before fortis consonants. Fortis consonants are slightly longer than lenis consonants, taking up part of the space otherwise available for lengthening. This would explain why the second vowel in $(15 b)$ is slightly shorter than the one in (15a), without the need of resorting to ILF feet-remember that fortis consonants coincide with the left edge of a foot and, hence, only (15b) contains a fortis consonant.

(15) Metrical parsings according to Hayes (1995)
a. (a.kú:) taq
b. (a. $\underline{\text { kú }})$ (ta.mék)

Unfortunately, Leer (1985c) does not provide a detailed description of the systematicity of the lengthening process, neither does he present exact durational values for the reported differences in length. Therefore, it is not possible to establish whether this lengthening distinction should be encoded in the phonological module of grammar (in the form of a constraint/rule that targets heads of two feet) or, by contrast, if it is just a matter of phonetic implementation, either resulting from the fortis nature of the following consonant (Hayes, 1995) or the phonetic interpretation of a double-headed syllable (15).

\section{ALTERNATIVE REPRESENTATIONS}

The number of CA stress analyses one can find in the literature is vast. In this section we briefly review just a few of the representations proposed earlier for the language, those that have most significantly influenced the present analysis, but differ from it in some crucial respects. The section closes with one more recent proposal for CA (Section 5.5), which crucially deviates form previous studies in the type of assumed prosodic representations.

\subsection{Leer (1985c)}

The original idea of positing an additional prosodic layer between the word and the metrical foot can already be tracked in the primary source of CA, that is, Leer (1985c). Likewise, this author was the first to point out that pitch in CA could be analyzed by reference to foot structure. However, Leer's approach differs from the present one in a few respects. On the one hand, Leer posited two intermediate levels between the prosodic word and the metrical foot rather than one: the Superfoot (SFt) and the Pitch Group (PG). To demonstrate that these categories are not mere notational variants of our ILT feet, compare Leer's representation on the left hand in Figure 3 a to ours with ILT feet on the right hand (Figure 3b).

Figure 3: Comparison of Leer's (1985c) pitch groups and superfeet in (a) vs. Internally Layered Feet (b).

a.

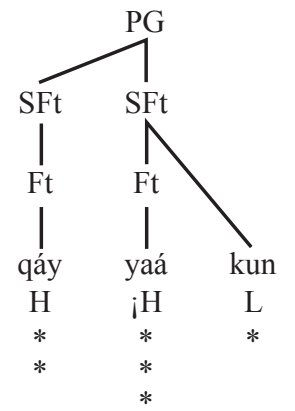

b.

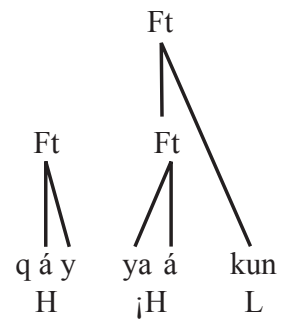


Leer's Superfoot is immediately above the foot; it sometimes coincides with the foot (the first SFt in Figure $3 \mathrm{a}$ ) and sometimes consists of a foot with an adjoined weak syllable (the second superfoot in Figure 3a), in a similar setup to our ILT foot. Furthermore, some pairs of superfeet can be grouped in a higher category, that is, the Pitch Group. According to Leer, pitch groups in CA are always right headed and consist of two superfeet, SFt1 and SFt2, but they are only built "if SFt1 is identical with the foot it dominates" (1985c, p. 168). The only raison d'etre of the category of the Pitch Group in Leer's account is to facilitate an account of up-stepping: pairs of $\mathrm{H}$ tones are grouped into pitch groups, the rightmost one been up-stepped. The stipulation that in a Pitch Group "SFt1 must be identical with the foot it dominates" needs to be made because when SFt1 includes an appended syllable (and hence, it is not identical with the foot it dominates) this appended syllable bears an L. However, recall that up-stepping only occurs when there is no intervening $\mathrm{L}$ between the two $\mathrm{H}$ syllables. Therefore, to avoid building a Pitch Group in case SFt1 is a ternary constituent, Leer must preclude the creation of a Pitch Group when SFt1 is not a binary foot. By contrast, we do not need to stipulate any of these specific requirements in our approach, in which the distribution of pitch is quite straightforward: Lows dock onto adjuncts of ILT feet, Highs dock onto foot heads and an OCP constraint triggers the up-stepping of some Highs.

Another illustrative example of Leer's Pitch Groups is provided below in (16). The specific tone of a syllable is indicated by the gridmarks: one gridmark corresponds to an $\mathrm{L}$ tone, two gridmarks to an $\mathrm{H}$ tone, three to an $\mathrm{H}$ upstepped. In (16) the right branch of the Pitch Group is up-stepped.

(16) PG and SFt in Leer (1985c, p. 170):

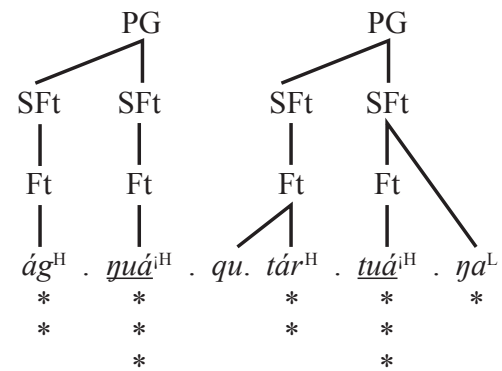

The metrical structure for this form in our approach would be the one shown in (17), with three standard binary feet and one final ILT foot.

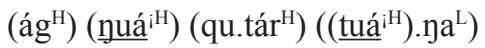

Leer does not provide independent motivation for these pitch groups, that is, these constituents are explicitly posited to create a domain for up-stepping. However, in Section 3 we demonstrated that this is not needed. Instead, the up-stepping can be explained by reference to one unique category independently needed to account for stress distri- butions the segmental phenomena, the ILT foot, and the postulation of an OCP constraint $\left(\mathrm{HH} \rightarrow \mathrm{H}_{i} \mathrm{H}\right)$, without the need of positing additional superfluous categories. Hence, there is no need to posit a Pitch Group.

Since Leer assumes that the Strict Layer Hypothesis is inviolable (i.e., prosodic levels cannot be skipped in prosodic representations; Selkirk, 1984), Leer's feet are all dominated by at least one superfoot, even when there is no evidence for such a superfoot. Many of the superfeet proposed by Leer thus coincide with the feet they dominate-e.g., the first syllable in (16) above. However, in these cases, it is not very clear why feet and superfeet constitute different categories, especially since they do not exhibit different phonological behavior.

Another minor difference between Leer's analysis and ours is that Leer makes use of two systems to mark prominence: the prosodic hierarchy and the metrical grid. In contrast, the ILT representation facilitates an account of stress and pitch by using only one prominence system (i.e., the metrical foot as a category in the prosodic hierarchy) and, thus, it is preferred for being more economical.

In sum, our reanalysis of CA owes much to Leer's insightful work, where the interconnection of stress, pitch and segmental phenomena was clearly made explicit more than three decades ago. We have just reconsidered his insights and aimed at unifying them in light of the theoretical advantages of the ILT foot.

\subsection{Resolved feet with binary heads}

It is important to clarify that the ILT foot is not a mere revival of Dresher and Lahiri's (1991), Rice's (1992) or Crowhurst's (1992) layered foot, known as resolved foot. As it can be seen in Figure 3, the resolved foot consists of an obligatory binary flat head plus an optional dependent. Dresher and Lahiri's (1991) and Rice's (1992) also used two representations to mark prominence, metrical structure and gridmarks (the square brackets delimit the complex head, while parentheses denote foot boundaries).

Figure 4: Resolved feet with a binary symmetric head (Dresher \& Lahiri, 1991; Rice, 1992).

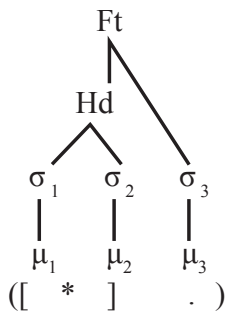

In a resolved foot the two first syllables display the same structure: as shown in Figure 4, they are both linked to the head constituent and, therefore, they are expected to present a similar phonological behavior. In contrast, in an ILT foot, the binary innermost constituent is not flat with respect to prominence, but it is actually a foot by itself, consisting of a foot dependent and a foot head. Hence, in an 
ILT foot model the true head of the ternary foot corresponds exclusively to one constituent: in Figure 4, the second mora. This subtle distinction is crucial in CA, where one of the syllables (or morae) in the binary head is systematically more prominent than the other. For instance, the first two syllables in a form like [((ta.qú $\left.\left.u^{\mathrm{H}}\right) \mathrm{ma}^{\mathrm{L}}\right)\left(\right.$ lu.ní $\left.\left.^{\mathrm{H}}\right)\right]$ behave phonologically differently: only the second syllable bears stress and a high pitch, and only the first syllable undergoes fortition of its onset. Hence, the resolved foot is principally unable to capture any metrically conditioned phenomena in which one of the elements in the head behaves as weaker or stronger than the other. For example, this structure would fail to capture the typological observation that in languages with iambic lengthening such as CA only the head's second syllable displays lengthening. The flat head also makes it impossible to account for cases in which the vowel of only one syllable in the binary head is reduced.

\subsection{Hewitt $(1991,1992)$}

We have proposed here an interpretation of the facts very similar to the one argued for in Hewitt $(1991,1992)$. However, rather than considering the possibility that feet are recursive and that the unstressed syllable is directly dominated by a foot, Hewitt claimed that the ternary category consisting of a foot and a light syllable is a bounded prosodic word. In fact, in Hewitt's account, binary feet without an adjunct also project a bounded prosodic word (Hewitt, 1991, p. 56; 1992, p. 77). This is illustrated in Figure 5 with a 5-mora form (for details, see Hewitt, 1991, § 2.2).

Figure 5: Adapted from Hewitt (1991, p. 50 and p. 53).

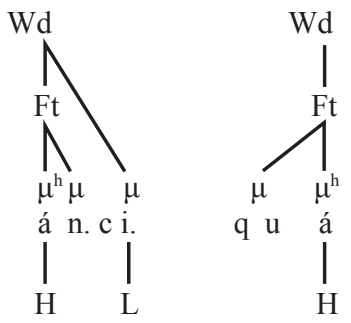

This author should be therefore credited for unifying the analysis of stress and pitch. Yet considering that this ternary constituent is a prosodic word rather than a foot faces a few problems. First, by multiplying the number and boundaries of prosodic words as in Figure 5, there is no simple way to formalize the weight-by-position restriction affecting word-initial CVC syllables (see Section 2.1). We interpreted this restriction to be a prominence effect affecting word-initial syllables. However, under Hewitt's representations it is not clear how to capture the generalization that a coda is only moraic in the first syllable, but not in other word-internal syllables, which in his analysis coincide with the left edge of a prosodic word.

Secondly, as suggested in Section 4, the ILT foot approach could also account for the reported extra length of vowels in the head of layered feet as opposed to vowels in the head on non-layered feet: only the former has a dou- ble-headed status. However, it is not clear how Hewitt's representations can account for the difference between long vs. half-long vowels, since in his analysis all foot heads display the same structure, that is, they are all heads of bounded prosodic words (see Figure 5).

Hewitt's key argument for positing a bounded prosodic word in CA is based on the distribution of pitch in Koniag Alutiiq (KA), a related Yupik dialect. In KA the $\mathrm{H}$ tone docks onto all syllables, except if a word with a final unstressed syllable has a final L tone. Based on the similarities of the dialects, Hewitt states that in CA and Koniag the underlying tone pattern is (L) H (L). In Koniag, the $\mathrm{H}$ docked onto the first foot head is spread to the other feet within the prosodic word (see Figure 6). To derive the alternating tonal pattern in CA as opposed to the more uniform KA pattern, Hewitt's proposal is that the domain of tone is the word. Since CA has multiple instances of bounded prosodic words, it also has iterating tone assignment. Figure 6 illustrates this proposal, assuming a word with light syllables. Feet are binary in KA.

Figure 6: Adapted from Hewitt (1992, p. 72).
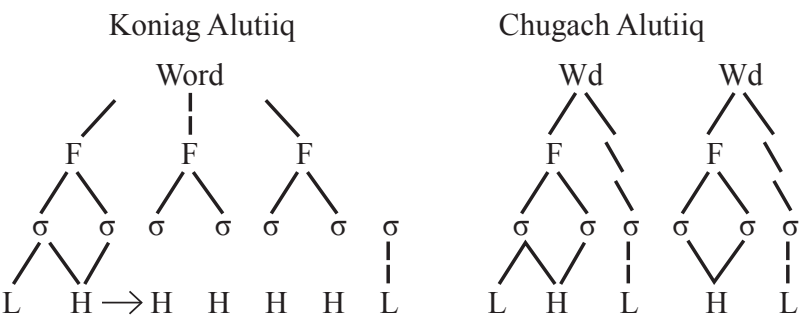

However, Rice (1992) states that "in personal communication, Leer reports that the pitch on initial unstressed light syllables [at least in CA] is actually an interpolation between the neighboring pitch values" (p. 147). Hence, word initial syllables in CA forms that start with a light syllable are not phonologically specified for a low tone. In a framework with ILT feet, the distributions of pitch in CA can be easily derived due to the different status of foot heads and foot dependents, in relation to a minimal foot or a non-minimal foot. There is no need to posit two bounded prosodic words to account for the iteration of a tonal melody in CA. In KA, where there are no ILT feet, an $\mathrm{H}$ is docked onto the first foot head and spread rightward within the prosodic word. In both dialects pitch is assigned to the morphological word, which in both dialects can be equated with the prosodic word, but in CA the additional feature of iterative foot formation has an immediate effect on the distribution of pitch.

Finally, Leer (1985a) describes a gemination process in CA (briefly referred to in footnote 5), which targets the onset of a second syllable that is heavy. As a result, a word-initial light syllable becomes heavy (e.g., /qayaatxun/ [qáy.yaát.xun] 'by their boats'). Within our proposal, gemination can be again interpreted to be a phonological enhancement process restricted to word-initial syllables, but with Hewitt's representations it is not so simple to restrict this process to absolute word-initial position be- 
cause the word-initial context is multiplied due to the bounded prosodic word.

In sum, although Hewitt's bounded prosodic word often coincides with our ILT foot, it is important to highlight that the former is not a mere notational variant of the latter. Some context-specific processes would remain unexplained. For this reason, it is crucial that the layer that consists of a foot and an adjoined syllable is characterized as a foot and not a prosodic word.

\subsection{Weak Local Parsing analyses}

Kager (1993) originally proposed the strictly bimoraic iamb $^{9}$ for $\mathrm{CA}$ in combination with Weak Local Parsing (WLP), a foot parsing mode proposed by Hayes (1995) for ternary stress (see also Elenbaas \& Kager, 1999). While binary rhythm involves a directional parsing of pairs of syllables into feet, that is, a back-to-back mode, WLP creates ternary rhythm by leaving a monomoraic syllable unparsed between feet. In Kager's analysis, after WLP, all unparsed syllables are stray-adjoined to the preceding bimoraic foot into a trimoraic surface foot.

$$
\begin{aligned}
& \text { After WLP } \\
& \text { (án) ci (quá) } \\
& \text { (a.tú) qu (ni.kí) } \\
& \text { (naá) qu (ma.lú) ku } \\
& \text { (pi.sú) qu (ta.qú) ni }
\end{aligned}
$$

$$
\begin{aligned}
& \text { After adjunction } \\
& \text { (án.ci) (quá) } \\
& \text { (a.tú.qu) (ni.kí) } \\
& \text { (naá.qu) (ma.lú.ku) } \\
& \text { (pi.sú.qu) (ta.qú.ni) }
\end{aligned}
$$

Note that the difference with the ILT analysis resides in the flatness of the ternary foot after stray adjunction. This is also a disadvantage of Kager's analysis: it cannot capture differences between two types of weak syllables regarding low pitch distribution which the ILT analysis easily captures in terms of status of dependents of minimal versus maximal feet. Conceptually, a WLP-plusstray-adjunction analysis uses two distinct mechanisms for metrical foot parsing, which makes it less uniform than the ILT foot analysis, which has one mechanism.

\subsection{Hyde (2001, 2002 et seq.)}

Hyde (2001, 2002 and subsequent work) proposes a radical modification of the types of metrical representations allowed by universal grammar, in particular the inclusion of ambipodal syllables. Ambipodal syllables are structurally bipolar in the sense of being simultaneously the head of one foot (Ftx) and the dependent of another foot (Fty). Consider a word with six light syllables in CA; in these forms, stress falls on the second and the fifth syllables as indicated by the gridmarks (Figure 7).
Figure 7: Hyde's ambipodal syllables to account for CA ternary stress (vertical lines indicate foot heads, diagonal lines signal foot dependents).
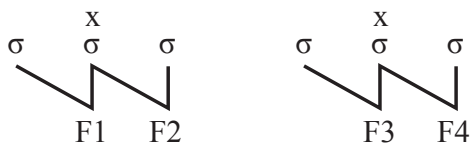

By virtue of their gridmark, these ambipodal syllables are the only ones that receive stress. Other syllables that are in a foot head position (e.g., the third and sixth syllables) surface without stress. There is ample evidence for the existence of stressless feet in several languages (e.g., Buckley, 2009, and references therein) and, thus, the fact that CA has stressless feet is not necessarily a drawback of Hyde's proposal. However, Hyde's assumption that the only syllables that receive stress in CA are the ones simultaneously located in a head and a dependent position is counterintuitive, since syllables that are in purely head positions would be expected to be slightly stronger than those that are in a head dependent position. Hence, within Hyde's proposal, the relation between prosodic structure and stress is looser than in standard theories; it also requires two systems/devices to mark prominence: the metrical grid and prosodic constituency (i.e., feet and syllables).

An analysis of CA in ambipodal terms (Figure 7) is also descriptively inadequate since consonant fortition can no longer be derived from foot-initial strengthening. Instead, these representations would predict fortition in the first, second, fourth and fifth syllable; however, fortition only targets the onsets of the first and fourth syllables (Section 2). Also, it is not clear how these representations can account for the distribution of pitch in the language. Recall that in a 6-syllable word, an $\mathrm{L}$ is docked onto the third and sixth syllables. To save Hyde's analysis, one could propose that Lows only dock onto genuine foot heads while excluding ambipodal syllables. However, this seems to contradict the crosslinguistic generalizations that report that foot heads tend to be associated with $\mathrm{H}$ tones, not $\mathrm{L}$ tones (Bickmore, 1995; de Lacy, 2002, 2006; Goldsmith, 1987).

To conclude, even if an ambipodal-syllable account is able to predict CA ternary rhythm, a recursion-based analysis still seems to be superior since it provides a unified and simpler account of several word-level phenomena.

\subsection{Overall evaluation of representational elements}

After reviewing several proposals for prosodic structure in CA, we can identify various positive and negative elements among them. Three outstanding positive elements of representation, which are shared by Leer (1985a), Hewitt (1991, 1992), and the current ILT proposal are the

\footnotetext{
9 Note that Kager's moraic iamb analysis improves over Hayes' (1995) analysis of CA based on the uneven iamb, where a trimoraic light-heavy foot is favored over bimoraic light-light and single heavy feet. An advantage of the moraic iamb is shown in cases such as /anciqua/, which is parsed as (án.ci)(quá) with two bimoraic iambs but as (án) (ci.quá) by uneven iambs. The later parsing is incorrect, based on fortition and low tone placement. See Kager (1993, p. 417 ff.) and Hayes (1995, p. 342 ff.) for discussion.
} 
following: (a) the strictly bimoraic foot (Foot in Leer, 1985a, and Hewitt, 1991, 1992; a minimal foot in our current proposal); (b) some type of recursive prosodic structure between the bimoraic foot (head) and the prosodic word (Superfeet in Leer, 1985a; bounded prosodic words in Hewitt, 1991, 1992; or ILT feet in our proposal); (c) monomoraic righthand adjuncts in recursive categories mentioned in (b). These three elements allow for a straightforward representation of ternary rhythm as well as footdependent segmental and tonal distributions in CA. Elements of representation that are less successful, and should be jettisoned include: (a) non-unique heads (resolved feet, Rice, 1992; ambipodal syllables, Hyde, 2001, 2002); (b) superfluous categories (the Pitch Group, Leer, 1985c; the maximal minimal word, Hewitt, 1991, 1992; the flat surface feet, Kager, 1993).

\section{CONCLUSIONS}

In this article we have presented arguments for the rehabilitation of the Internally Layered Ternary (ILT) foot in metrical representations, based on converging evidence from Chugach Alutiiq from several sources: its mixed ternary-binary rhythmic pattern as well as three foot governed segmental and prosodic phenomena-consonant fortition, extra long vowel lengthening and the complex distribution of tones. We have showed ILT feet to be proper domains for these phenomena allowing maximally simple statements of their contexts, as foot-initial, double-head status and dependent of a non-minimal foot, respectively. The convergence of four complex distributions (stress, fortition, vowel duration, and pitch) by a single prosodic constituent is strong evidence for the ILT foot as element of prosodic theory. Yet, inclusion of ILT in prosodic theory does not amount to the addition of a primitive, since ILT feet are derived simply by adjunction of a single syllable to the classical category foot. A minimally recursive structure after adjunction is all that is needed to give all of the beneficial effects.

The analysis of CA adds to a pre-existing body of analyses based on ILT feet, reported in studies such as Martínez-Paricio and Kager (2015), and references in the introduction of this article. We believe that future exploration of the prosodic systems of natural languages as well as their metrically dependent phenomena will reveal further cases and evidence for the ILT foot.

\section{ACKNOWLEDGMENTS}

The present paper is based on chapter 4 of the first author's PhD dissertation, from the University of Tromsø, and was written thanks to a postdoctoral grant from the Valencian Government (APOSTD/2016/120) and the support of the Spanish Ministry of Economy and Competitiveness (FFI2013-46987-C3-1-P). The second author's research was supported by the Netherlands Organisation for Scientific Research (NWO) in the framework of the project 'Parsing and metrical structure: Where phonology meets processing' (360-89-030).

\section{REFERENCES}

Beckman, J. N. (1998). Positional faithfulness (Doctoral dissertation). University of Massachussetts Amherst. Retrieved from http://roa.rutgers.edu/files/234-1297/234-1297-BECKMAN-6-0.PDF

Bennett, R. T. (2012). Foot-conditioned phonotactics and prosodic constituency (Doctoral dissertation). Santa Cruz: University of California.

Bickmore, L. S. (1995). Tone and stress in Lamba. Phonology, 12(3), 307-341. http://oadoi.org/10.1017/S0952675700002542

Buckley, E. (2009). Locality in metrical typology. Phonology, 26(3), 389-435. http://oadoi.org/10.1017/S0952675709990224

Crowhurst, M. J. (1992). Minimality and foot structure in metrical phonology and prosodic morphology. Bloomington, IL: Indiana University Linguistics Club.

Davis, S., \& Cho, M.-H. (2003). The distribution of aspirated stops and $/ \mathrm{h} /$ in American English and Korean: An alignment approach with typological implications. Linguistics, 41(4), 607652. http://oadoi.org/10.1515/ling.2003.020

De Lacy, P. (2002). The interaction of tone and stress in Optimality Theory. Phonology, 19(1), 1-32. http://oadoi.org/10.1017/S095 2675702004220

De Lacy, P. (2004). Markedness conflation in Optimality Theory. Phonology, 21(2), 145-199. http://oadoi.org/10.1017/S0952675 704000193

De Lacy, P. (2006). Markedness: Reduction and preservation in phonology. Cambridge: Cambridge University Press. http:// oadoi.org/10.1017/CBO9780511486388

Dresher, B. E., \& Lahiri, A. (1991). The Germanic foot: Metrical coherence in Old English. Linguistic Inquiry, 22(2), 251-286.

Elenbaas, N., \& Kager, R. (1999). Ternary rhythm and the lapse constraint. Phonology, 16(3), 273-329. http://oadoi.org/10.1017/ S0952675799003772

Goldsmith, J. (1976). Autosegmental phonology (Doctoral dissertation). MIT [Published in 1979, New York: Garland].

Goldsmith, J. (1987). Tone and accent, and getting the two together. In J. Aske, N. Beery, L. Michaelis \& H. Filip (Eds.), Proceedings of the 13th Annual Meeting of the Berkeley Linguistic Society (pp. 88-104). http://oadoi.org/10.3765/bls.v13i0.1827

Gordon, M. (2002). A factorial typology of quantity-insensitive stress. Natural Language \& Linguistic Theory, 20(3), 491-552. http://oadoi.org/10.1023/A:1015810531699

Green, T., \& Kenstowicz, M. (1996). The lapse constraint. Proceedings of the 6th Annual Meeting of the Formal Linguistics Society of the Midwest (pp. 1-15).

Grijzenhout, J. (1990). Modern Icelandic foot formation. In R. Bok-Bennema \& P. Coopmans (Eds.), Linguistics in the Netherlands (pp. 53-62). Dordrecht: Foris.

Gussenhoven, C. (2004). The phonology of tone and intonation. Cambridge: Cambridge University Press. http://oadoi.org/ 10.1017/CBO9780511616983

Halle, M. (1990). Respecting metrical structure. Natural Language \& Linguistic Theory, 8(2), 149-176. http://oadoi.org/10.1007/ BF00208522

Halle, M., \& Vergnaud, J.-R. (1987). An essay on stress. Cambridge, MA: MIT Press.

Hammond, M. (1995). Deriving ternarity. University of Arizona Linguistics Circle. Retrieved from http://hdl.handle.net/10150/ 311745 .

Hayes, B. P. (1980/1985). A metrical theory of stress rules. New York: Garland Press.

Hayes, B. (1995). Metrical stress theory: Principles and case studies. Chicago, IL: Chicago University Press.

Hewitt, M. S. (1991). Binarity and ternarity in Alutiiq. In J. Ann \& K. Yoshimura (Eds.), Proceedings of Arizona phonology 
conference, Vol. 4 (pp. 44-60). Retrieved from http://hdl.handle.net $/ 10150 / 227270$

Hewitt, M. S. (1992). Vertical maximization and metrical theory (Doctoral dissertation). Waltham, MA: Brandeis University.

Houghton, P. (2006). Ternary stress. Amherst: University of Massachusetts. Retrieved from http://roa.rutgers.edu/files/8360606/836-HOUGHTON-0-0.PDF

Hulst, H. van der (2010). A note on recursion in phonology. In H. v. d. Hulst (Ed.), Recursion and human language. De Gruyter Mouton. http://oadoi.org/10.1515/9783110219258.299

Hyde, B. (2001). Metrical and prosodic structure in optimality theory (Doctoral dissertation). New Brunswick, NJ: Rutgers University.

Hyde, B. (2002). A restrictive theory of metrical stress. Phonology, 19(3), 313-359. http://oadoi.org/10.1017/S0952675703004391

Hyde, B. (2015). Overlap, recursion, and ternary constructions. Paper presented at the Workshop on Formal Typologies, Rutgers University.

Hyman, L. M. (1985). A theory of phonological weight. Dordrecht: Foris.

Idsardi, W. J. (1992). The computation of prosody (Doctoral dissertation). Massachusetts Institute of Technology.

Ito, J., \& Mester, A. (2007). Prosodic adjunction in Japanese compounds. MIT Working Papers in Linguistics, 55, 97-111.

Ito, J., \& Mester, A. (2009). The onset of the prosodic word. In S. Parker (Ed.), Phonological argumentation: Essays on evidence and motivation (pp. 227-260). London: Equinox.

Ito, J., \& Mester, A. (2013). Prosodic subcategories in Japanese. Lingua, 124, 20-40. http://oadoi.org/10.1016/j.lingua.2012.08.016

Jacobson, S. (1985). Siberian Yupik and Central Yupik prosody. In M. Krauss (Ed.), Yupik Eskimo prosodic systems: Descriptive and comparative studies (pp. 25-46). Fairbanks: Alaska Native Language Center, University of Alaska.

Jensen, J. T. (2000). Against ambisyllabicity. Phonology, 17(2), 187-235. http://oadoi.org/10.1017/S0952675700003912

Kager, R. (1989). A metrical theory of stress and destressing in English and Dutch. Dordrecht: Foris.

Kager, R. (1993). Alternatives to the iambic-trochaic law. Natural Language \& Linguistic Theory, 11(3), 381-432. http://oadoi. org/10.1007/BF00993165

Kager, R. (1994). Ternary rhythm in alignment theory. Retrieved from http://roa.rutgers.edu/files/35-1094/35-1094-KAGER-0-0. PDF

Kager, R. (2012). Stress in windows: Language typology and factorial typology. Lingua, 122(13), 1454-1493. http://oadoi. org/10.1016/j.lingua.2012.06.005

Kager, R., \& Martínez-Paricio, V. (forthcoming a). The internally layered foot in Dutch.

Kager, R., \& Martínez-Paricio, V. (forthcoming b). Mora and syllable accentuation-Typology and representation.

Leer, J. (1985a). Prosody in Alutiiq. In M. Krauss (Ed.), Yupik Eskimo prosodic systems: Descriptive and comparative studies (pp. 77-134). Fairbanks: Alaska Native Language Center, University of Alaska.

Leer, J. (1985b). Evolution of prosody in the Yupik languages. In M. Krauss (Ed.), Yupik Eskimo prosodic systems: Descriptive and comparative studies (pp. 135-158). Fairbanks: Alaska Native Language Center, University of Alaska.

Leer, J. (1985c). Toward a metrical interpretation of Yupik prosody. In M. Krauss (Ed.), Yupik Eskimo prosodic systems: Descriptive and comparative studies (pp. 159-173). Fairbanks: Alaska Native Language Center, University of Alaska.

Liberman, M. (1975). The intonational system of English (Doctoral dissertation). Massachusetts Institute of Technology.

Liberman, M., \& Prince, A. (1977). On stress and linguistic rhythm. Linguistic Inquiry, 8(2), 249-336.
Martínez-Paricio, V. (2012). Superfeet as recursion. In N. Arnett \& R. Bennett (Eds.), Proceedings of the 30th West Coast Conference on Formal Linguistics (pp. 259-269). Somerville, MA: Cascadilla Proceedings Project. Available online at http://www. lingref.com/cpp/wccfl/30/paper2823.pdf

Martínez-Paricio, V. (2013). An exploration of minimal and maximal metrical feet (Doctoral dissertation). University of Tromsø.

Martínez-Paricio, V., \& Kager, R. (2015). The binary-to-ternary rhythmic continuum in stress typology: Layered feet and nonintervention constraints. Phonology, 32(3), 459-504. http:// oadoi.org/10.1017/S0952675715000287

McCarthy, J. J. (1982). Prosodic structure and expletive infixation. Language, 58(3), 574-590. http://doi.org/10.2307/413849

McCarthy, J. J., \& Prince, A. (1986/1996). Prosodic morphology. Technical report no. 32, Rutgers Center for Cognitive Science.

McCartney, S. J. (2003). Ternarity through binarity (Doctoral dissertation). Austin: University of Texas.

Nespor, M., \& Vogel, I. (1986). Prosodic phonology. Dordrecht: Foris.

Pierrehumbert, J. (1980). The phonetics and phonology of English intonation (Doctoral dissertation). Bloomington, IN: Indiana University Linguistics Club.

Prince, A. S. (1980). A metrical theory for Estonian quantity. Linguistic Inquiry, 11(3), 511-562.

Prince, A. (1991). Quantitative consequences of rhythmic organization. In K. Deaton, M. Noske \& M. Ziolkowski (Eds.), Papers from the Parasession on the syllable in phonetics and phonology, 26, Vol. 2 (pp. 355-398). Chicago, IL: Chicago Linguistic Society.

Prince, A., \& Smolensky, P. (1993/2004). Optimality theory: Constraint interaction in generative grammar. Malden, MA: Blackwell.

Rice, C. (1988). Stress assignment in the Chugach dialect of Alutiiq. In D. Brentari, G. Larson \& L. MacLeod (Eds.), Proceedings of the Chicago Linguistic Society, 24 (pp. 304-315). Chicago, IL: Chicago Linguistic Society.

Rice, C. (1992). Binarity and ternarity in metrical theory: Parametric extensions (Doctoral dissertation). University of Texas at Austin.

Rice, C. (2007). The roles of Gen and Con in modeling ternary rhythm. In S. Blaho, P. Bye \& M. Krämer (Eds.), Freedom of analysis? (pp. 233-255). Berlin: Walter de Gruyter.

Rice, C. (2011). Ternary rhythm. In M. v. Oostendorp, C. J. Ewen, E. Hume \& K. Rice (Eds.), The Blackwell companion to phonology, Vol. 5 (pp. 1228-1244). Malden, MA: Blackwell.

Rosenthall, S., \& Hulst, H. v. d. (1999). Weight-by-position by position. Natural Language \& Linguistic Theory, 17(3), 499-540. http://oadoi.org/10.1023/A:1006283229291

Selkirk, E. O. (1978). The French foot: On the status of 'mute' e. Journal of French Linguistics, 1, 141-150.

Selkirk, E. O. (1980). The role of prosodic categories in English word stress. Linguistic Inquiry, 11(3), 563-605.

Selkirk, E. O. (1984). Phonology and syntax: the relation between sound and structure. Cambridge, MA: MIT Press.

Smith, J. L. (2005). Phonological augmentation in prominent positions. New York: Routledge.

Vijver, R. van der (1998). The iambic issue: Iambs as a result of constraint interaction. The Hague: Holland Academic Graphics.

Woodbury, A. C. (1987). Meaningful phonological processes: A consideration of Central Alaskan Yupik Eskimo prosody. Language, 63(4), 685-740. http://oadoi.org/10.2307/415716

Yip, M. J. (2002). Tone. Cambridge: Cambridge University Press. http://oadoi.org/10.1017/CBO9781139164559

Zoll, C. (2004). Ternarity vs. Final exclusion: A synthesis. Massachusetts Institute of Technology. [Not consulted] 